\title{
Hypodontia-dysplasia of nails syndrome
}

INSERM

\section{Source}

INSERM. (1999). Orphanet: an online rare disease and orphan drug data base.

Hypodontia-dysplasia of nails syndrome. ORPHA:2228

Hypodontia-nail dysplasia syndrome is a form of ectodermal dysplasia. 